\title{
Phosgene in the UTLS: seasonal and latitudinal variations from MIPAS observations
}

\author{
Massimo Valeri ${ }^{1,2}$, Massimo Carlotti ${ }^{3}$, Jean-Marie Flaud ${ }^{4}$, Piera Raspollini ${ }^{5}$, Marco Ridolfi ${ }^{2,5}$, and Bianca \\ Maria Dinelli ${ }^{1}$ \\ ${ }^{1}$ ISAC-CNR - Istituto di Scienze dell' Atmosfera e del Clima, Via Gobetti 101, 40129 Bologna, Italy \\ ${ }^{2}$ Dipartimento di Fisica e Astronomia, Università di Bologna, Viale Berti Pichat 6/2, 40127 Bologna, Italy \\ ${ }^{3}$ Dipartimento di Chimica Industriale "Toso Montanari“, Università di Bologna, \\ Viale del Risorgimento 4, 40136 Bologna, Italy \\ ${ }^{4}$ LISA - Laboratoire Interuniversitaire des Systémes Atmosphériques, 61 avenue du Général de Gaulle, Créteil, France \\ ${ }^{5}$ IFAC-CNR - Istituto di Fisica Applicata "Nello Carrara", Via Madonna del Piano 10, 50019 Sesto Fiorentino, Italy
}

Correspondence to: Massimo Valeri (m.valeri@isac.cnr.it)

Received: 29 February 2016 - Published in Atmos. Meas. Tech. Discuss.: 2 May 2016

Revised: 27 July 2016 - Accepted: 5 August 2016 - Published: 20 September 2016

\begin{abstract}
The Michelson Interferometer for Passive Atmospheric Sounding (MIPAS) is a Fourier transform spectrometer that measured mid-infrared atmospheric limb emission spectra from July 2002 to April 2012 on board the polarorbiting satellite ENVISAT. We have used MIPAS data to study the latitudinal variations of phosgene $\left(\mathrm{COCl}_{2}\right.$ or carbonyl chloride) and, for the first time, its seasonal variation in the upper troposphere/lower stratosphere region (UTLS). Retrievals of phosgene were made using the $830-860 \mathrm{~cm}^{-1}$ region, corresponding to the $v_{5}$ bands of $\mathrm{COCl}_{2}$. Unfortunately, in that region, the $v_{4}$ band of CFC-11, which is much stronger than $\mathrm{COCl}_{2} v_{5}$, hides the phosgene emission. In order to evaluate seasonality and latitudinal distribution of phosgene we have analysed all the measurements made by MIPAS on days 18 and 20 of each month of 2008 with the optimized retrieval model (ORM) recently upgraded with the multi-target retrieval technique and with the optimal estimation functionality to apply external constraints to the state vector. Average seasonal profiles of phosgene show an evident latitudinal variability with the largest values observed in the tropical regions (maximum $\approx 35$ parts per trillion by volume (pptv) at about $300 \mathrm{hPa}$ ). In the midlatitude and polar regions, the volume mixing ratio (VMR) values do not exceed $30 \mathrm{pptv}$ and the vertical distributions are less peaked. Our analysis highlights that $\mathrm{COCl}_{2}$ seasonal variability is fairly low, apart from the polar regions.
\end{abstract}

\section{Introduction}

Carbonyl chloride $\left(\mathrm{COCl}_{2}\right)$, better known as phosgene, is a toxic gas. In the 20th century phosgene was mainly used by the chemical industry in the preparation of insecticides, pharmaceuticals and herbicides. Its usage has been reduced over the years due to its high toxicity. Atmospheric phosgene is also formed in the troposphere (Fu et al., 2007; Kindler et al., 1995) by OH-initiated oxidation of chlorinated hydrocarbons such as $\mathrm{CHCl}_{3}$ (chloroform), $\mathrm{CH}_{3} \mathrm{CCl}_{3}$ (methylchloroform), $\mathrm{C}_{2} \mathrm{Cl}_{4}$ (tetrachloroethylene) and $\mathrm{C}_{2} \mathrm{HCl}_{3}$ (trichloroethylene). In the stratosphere it is formed by oxidation of its tropospheric source molecules and by the photochemical decay of $\mathrm{CCl}_{4}$ (carbon tetrachloride). Stratospheric phosgene is a weak absorber in the UV region and has a long lifetime (several years); however it is slowly oxidised to form $\mathrm{ClO}_{X}$. By contrast, the lifetime of phosgene in the troposphere is shorter (about 70 days), because it is rapidly removed by water droplets or by deposition in the oceans (Singh, 1976; Kindler et al., 1995).

The first study about atmospheric phosgene was made by Singh (1976). This author studied the surface distribution of phosgene using data from six stations in California. In 1988, Wilson et al. (1988) measured phosgene at various altitudes during an aircraft flight over Germany. Toon et al. (2001) used the Jet Propulsion Laboratory (JPL) MkIV interferometer, on board stratospheric balloons, to retrieve different volume mixing ratio (VMR) profiles of phosgene from 1992 to 
2000. The first satellite measurements of stratospheric phosgene have been performed using the Atmospheric Chemistry Experiment Fourier transform spectrometer (ACE-FTS) on board the SCISAT-1 satellite. Fu et al. (2007) used ACEFTS measurements in the period between February 2004 and May 2006 to make the first analysis of the global distribution of phosgene. Using data acquired by the same experiment in the years from 2004 to 2010, Brown et al. (2011) focused on the study of the trends of the halogen species, including phosgene. In the thermal infrared, phosgene can be measured in the $830-860 \mathrm{~cm}^{-1}$ spectral region, corresponding to the $v_{5}$ band of $\mathrm{COCl}_{2}$. However, in the same spectral region, the $v_{4}$ band of $\mathrm{CCl}_{3} \mathrm{~F}$ (CFC-11) is present. The emission of the CFC-11 $v_{4}$ band is much stronger than the one of $\mathrm{COCl}_{2} \nu_{5}$ band; therefore phosgene spectral features are hidden by the CFC-11 absorbing band. In the validation phase of Michelson Interferometer for Passive Atmospheric Sounding (MIPAS) version 6 products, obtained with the ESA level 2 processor, positive biases were found in the CFC-11 VMR profiles. In particular, CFC-11 profiles were found to be affected by a significant bias at all altitudes and latitudes with respect to MIPAS balloon measurements (ML2PP, 2012; Wetzel et al., 2014) and Bonbon (Schmidt et al., 1987) measurements (Engel et al., 2016). While below $19 \mathrm{~km}$ this bias was still within the combined systematic and total errors, above this altitude it clearly exceeded this error margin. From the study of the residuals of the CFC-11 retrievals, no particular features emerged but, while checking the atmospheric molecules absorbing in the same spectral range, it was found that $\mathrm{COCl}_{2}$ had not been included in the computation of the simulated spectra. A preliminary test was performed which took into account $\mathrm{COCl}_{2}$ interference in the simulated spectra using the vertical distribution retrieved by ACE-FTS (Fu et al., 2007) and $\mathrm{COCl}_{2}$ cross sections recorded at $25^{\circ} \mathrm{C}$ by Sharpe et al. (2004). The results of this test indicated that the differences in the average retrieved CFC-11 with and without $\mathrm{COCl}_{2}$ included in the simulation were of the order of the bias found in CFC-11 profiles. Therefore, in subsequent retrievals of MIPAS CFC-11, phosgene has been added to the absorber list. The accuracy of the absorption cross section used in MIPAS retrievals is quite good but unfortunately the temperature range of the cross-section measurements is far from being adequate for atmospheric retrievals. This fact triggered the development of new spectroscopic data for phosgene in order to enable a better reproduction of its contribution to MIPAS spectra (Kwabia-Tchana et al., 2015). Furthermore, the clear interference of phosgene into the CFC-11 signal suggested that MIPAS measurements could be exploited to retrieve phosgene global distributions. Being based on the limb emission technique, MIPAS provides measurements with global coverage day and night for a long time period. In this paper, we present the vertical distribution of phosgene, measured for the first time from MIPAS observations using newly developed spectroscopic information. Due to the large spatial and temporal coverage of MI-
PAS, we have investigated the seasonal and latitudinal variation of phosgene. The paper is organised as follows. Section 2 gives a brief overview of the MIPAS measurements. Section 3 describes the analysis scheme used for the retrieval of phosgene. Section 4 describes the MIPAS observations used in this analysis, the associated diagnostic data and the results obtained. Finally, Sect. 5 contains the conclusions.

\section{MIPAS measurements}

MIPAS (Fischer et al., 2008) is a Fourier transform spectrometer that measured atmospheric limb emission spectra from a polar sun-synchronous orbit on board the European ENVISAT satellite from July 2002 to April 2012. The measured spectra cover the mid-infrared region, from 680 to $2410 \mathrm{~cm}^{-1}$. The $0.025 \mathrm{~cm}^{-1}$ spectral resolution adopted for the nominal measurements of the initial part of the mission (Full Resolution; FR mission) was interrupted in March 2004 to cope with a mechanical problem of the interferometric movement. MIPAS nominal measurements were then resumed in January 2005 with a reduced spectral resolution of $0.0625 \mathrm{~cm}^{-1}$. This resolution also implied a reduced time necessary for the measurement of the individual interferograms, allowing for a finer horizontal and vertical sampling of the atmosphere. Due to this last feature, the measurements acquired from January 2005 onward (Raspollini et al., 2013) are referred to as the Optimized Resolution (OR) mission. The MIPAS measurements considered in this paper refer only to the nominal operation mode of the OR mission. In this mode the horizontal separation between adjacent limb scans is approximately $410 \mathrm{~km}$. Each limb scan samples the altitude range from 6 to $71 \mathrm{~km}$ with 27 sweeps. The vertical sampling step is as fine as $1.5 \mathrm{~km}$ in the $6-21 \mathrm{~km}$ range of the upper troposphere/lower stratosphere (UTLS), then it smoothly degrades at higher altitudes. The whole vertical scan pattern is shifted along the orbit in order to roughly follow the tropopause altitude that changes with latitude. MIPAS interferograms are transformed into geolocated and radiometrically calibrated spectra by the so-called Level $1 \mathrm{~b}$ processor (Kleinert et al., 2007).

\section{Analysis}

The retrieval scheme used in this work is based on the optimized retrieval model (ORM) (Ridolfi et al., 2000; Raspollini et al., 2006, 2013), which is the scientific prototype of the Level 2 MIPAS retrieval algorithm used by ESA to routinely process MIPAS spectra. In order to make the retrieval of phosgene from its extremely weak spectral features feasible, we have used a version of the ORM upgraded with the multitarget retrieval (MTR) functionality (Dinelli et al., 2004) and with the possibility of using the optimal estimation (OE, or maximum a posteriori likelihood) approach (Rodgers, 2000) to apply external constraints to the state vector. This up- 
graded retrieval code has been validated within the so-called "Support to MIPAS Level 2 processor Verification and Validation - Phase F" ESA-supported project and will be the basis for the final release by ESA of the Level 2 MIPAS retrieval algorithm, for MIPAS data analysis. The MTR approach provides an opportunity to retrieve multiple target gases simultaneously from the same set of observations. This feature is particularly useful when the gas to be retrieved shows spectral signatures interfering with those of another gas for which the distribution in the atmosphere is unknown. With this approach, the mutual spectral interference of the retrieved gases is properly taken into account, thus avoiding the systematic error that would show up in a sequential retrieval. Given the strong spectral interference between $\mathrm{COCl}_{2}$ and CFC-11 already mentioned in Sect. 1, the MTR functionality can be regarded as fundamental to our work. The OE approach permits the application of external constraints to the inversion and is particularly helpful in the retrieval of very weak species. Moreover, $\mathrm{OE}$ enables the quality of the retrieved profiles to be monitored using the individual information gain quantifier described in Dinelli et al. (2009). This quantifier allows data to be filtered out for which the information extracted from the measurements is below a predefined threshold.

\subsection{Spectroscopic data of $\mathrm{COCl}_{2}$}

Phosgene is a heavy molecule with small rotational constants and with a number of low-lying vibrational states. As a consequence, at room temperature its infrared spectrum is extremely dense and almost intractable. Kwabia-Tchana et al. (2015) carried out the first detailed and extensive analysis of the $11.75 \mu \mathrm{m}$ absorption region of phosgene using highresolution Fourier transform spectra recorded at the low temperature of $169 \mathrm{~K}$. More precisely the $v_{5}$ bands of the two isotopologues $\mathrm{CO}^{35} \mathrm{Cl}_{2}$ and $\mathrm{CO}^{35} \mathrm{Cl}^{37} \mathrm{Cl}$ were assigned up to very high quantum numbers. The upper state ro-vibrational levels were fitted using Hamiltonian matrices, accounting for resonance effects when necessary. In this way, very satisfactory fits (to within the experimental accuracies) were obtained, leading to very accurate Hamiltonian constants and line positions. Unfortunately it was not possible to firmly assign the corresponding hot bands, which were modelled using extrapolated Hamiltonian constants. The new Hamiltonian constants were used to build the phosgene spectroscopic database used in this work. The line intensities used in our analysis were calculated using single transition moments (no rotational corrections) and calibrated using the crosssection measurements from Sharpe et al. (2004). Since no measurements of the pressure-broadening coefficients have been performed, a constant value of $0.8 \mathrm{~cm}^{-1} \mathrm{~atm}^{-1}$ for airbroadening and of $0.3 \mathrm{~cm}^{-1} \mathrm{~atm}^{-1}$ for self-broadening have been used. The error of the new phosgene spectroscopic database is dominated by the accuracy with which the cross sections have been measured (Sharpe et al., 2004).

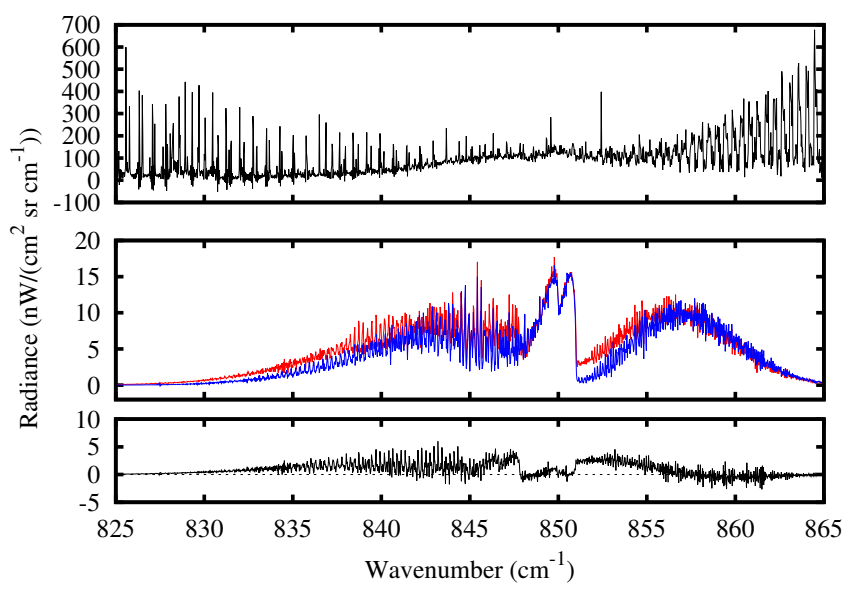

Figure 1. Top panel: simulated spectra at $21.2 \mathrm{~km}$ tangent altitudes for midlatitude atmospheric conditions in the $825-865 \mathrm{~cm}^{-1}$ spectral region using the mipas_pf4.45 database containing the new phosgene lines. Middle panel: contribution of the new phosgene linelist (red line) and of the ATMOS 1995 phosgene lines (blue line). Bottom panel: difference between the new phosgene linelist and the ATMOS 1995 database.

Previous satellite analysis of phosgene (Toon et al., 2001; Fu et al., 2007) were carried out using the 1995 Atmospheric Trace Molecule Spectroscopy (ATMOS) linelist (Brown et al., 1996). To evaluate the difference of the new spectroscopic data with respect to the older database, we have simulated a MIPAS spectrum at $21.2 \mathrm{~km}$ tangent altitude for midlatitude atmospheric conditions in the $800-900 \mathrm{~cm}^{-1}$ spectral region using the mipas_pf4.45 database (Perrin et al., 2016) where the new phosgene lines have been included and repeated the simulation using the same spectroscopic database where the phosgene lines were replaced by those from the ATMOS line list. Fig. 1 shows, in the upper panel, the simulated spectrum, while in the middle panel we report the contribution to the spectrum due to phosgene for our database (in red) and for the ATMOS database (in blue). The lowest panel of Fig. 1 shows the difference between the two phosgene spectra. The comparison between the two phosgene contributions shows that in the Q-branch region the two databases are in agreement, while higher radiances (about $\left.3 \mathrm{nW}\left(\mathrm{cm}^{2} \mathrm{srcm}^{-1}\right)^{-1}\right)$ are found for the new phosgene lines in the $\mathrm{P}$ and $\mathrm{R}$ branches.

\subsection{Retrieval method}

Our retrievals are based on the fit of a set of narrow $\left(3 \mathrm{~cm}^{-1}\right)$ spectral intervals called MicroWindows (MWs) containing relevant information on the target parameters. The MWs for MIPAS retrievals have been selected with the MWMAKE algorithm (Dudhia et al., 2002). MWMAKE identifies the spectral intervals to be analysed for a particular target with the aim of minimising the total retrieval errors (both systematic and random). This is done through the use of pre- 
Table 1. MWs selected for MTR retrievals of $\mathrm{COCl}_{2}$ and $\mathrm{CFC}-11$.

\begin{tabular}{cc}
\hline $\begin{array}{c}\text { Starting wavenumber } \\
\left(\mathrm{cm}^{-1}\right)\end{array}$ & $\begin{array}{c}\text { Ending wavenumber } \\
\left(\mathrm{cm}^{-1}\right)\end{array}$ \\
\hline 815.6875 & 818.6875 \\
818.7500 & 821.7500 \\
836.6875 & 839.6875 \\
839.7500 & 842.7500 \\
842.8125 & 845.8125 \\
846.9375 & 849.9375 \\
850.2500 & 853.2500 \\
857.1875 & 860.1875 \\
\hline
\end{tabular}

computed jacobians and error spectra. For the selection of phosgene MWs we computed the phosgene jacobians using the spectroscopic data described in Sect. 3.1 and the VMR climatological profiles included in the IG2 database (Remedios et al., 2007). This is a database containing climatological vertical distributions of atmospheric species relevant to MIPAS data inversion. The profiles are tabulated for different latitude bands and seasons. Latitude-dependent phosgene profiles have recently been added to the IG2 database.

The use of $\mathrm{OE}$ in the retrievals requires an a priori estimate of both the target profile and of its error covariance matrix. In order to minimise the influence of the a priori information on the observed latitudinal and seasonal variations of the retrieved $\mathrm{COCl}_{2} \mathrm{VMR}$, we used the same a priori profile and covariance matrix for all the retrievals presented in this work. We built the a priori profile of $\mathrm{COCl}_{2}$ by averaging all the IG2 profiles for the different latitudinal bands (no variation of phosgene with season is included into the IG2 database). Since the retrieved phosgene profiles presented in this paper have been averaged using a common pressure grid, we tabulated the a priori $\mathrm{COCl}_{2}$ profile onto the same pressure grid. This makes the a priori profile of $\mathrm{COCl}_{2}$ different for each retrieval when represented as a function of the altitude coordinate, but makes its shape invariant as a function of pressure. To build the a priori covariance matrix we assumed a $\mathrm{COCl}_{2}$ variability equal to $80 \%$ of the a priori profile, plus a constant absolute error of $10 \mathrm{pptv}$. Moreover, in order to introduce a weak vertical constraint in the retrieved $\mathrm{COCl}_{2}$ profiles, for the calculation of the a priori covariance matrix we assumed a vertical correlation length of $5 \mathrm{~km}$ (Steck and von Clarmann, 2001).

MWMAKE was used to select a set of MWs optimized for the retrieval of the $\mathrm{COCl}_{2}$ VMR profile as a single target. With these $\mathrm{MWs}, \mathrm{COCl}_{2}$ was individually retrieved after the sequential retrieval of the following targets: tangent pressure $(p)$, temperature $(T)$ and the VMR of $\mathrm{H}_{2} \mathrm{O}$, $\mathrm{O}_{3}, \mathrm{HNO}_{3}, \mathrm{NO}_{2}$, CFC-11, CFC-12, CFC-22. This approach, however, did not provide satisfactory results since it produced a double-peaked artefact at low altitudes in the zonally averaged $\mathrm{COCl}_{2}$ VMR profiles. Tests showed that this

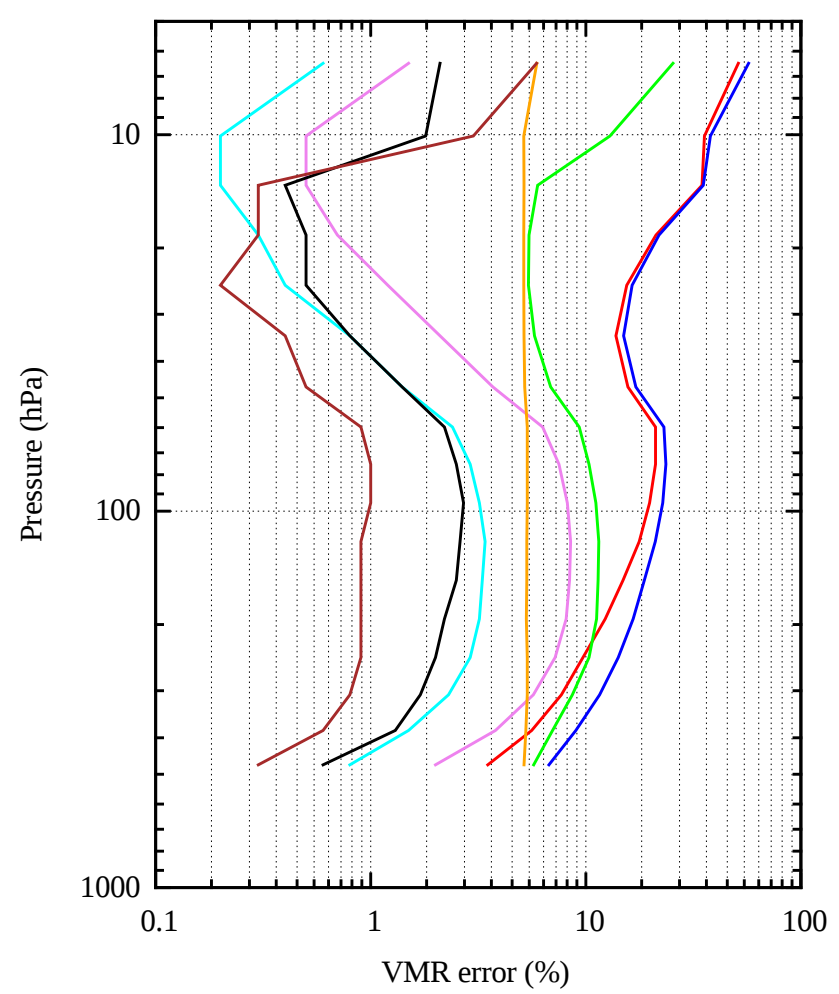

Figure 2. Error analysis of the joint $\mathrm{COCl}_{2}$ and $\mathrm{CFC}-11$ retrieval: the total error (blue), the total systematic error (green) and the total random error (red). We also report the uncertainties due to temperature (violet), pressure (cyan), spectroscopic database (orange-red), intensity calibration (black) and to the width of the instrument line shape (brown) for the phosgene VMR.

artefact was due to the mutual spectral interference between $\mathrm{COCl}_{2}$ and CFC-11 (Kellmann et al., 2012). As already said in Sect. 1 such a strong interference had already been highlighted in the validation phase of MIPAS CFC-11 version 6 profiles. Even if CFC-11 was retrieved from the same scan in a previous step of the retrieval chain, the error affecting the retrieved profile was large enough to produce the unrealistic artefact. Therefore we decided to account for the spectral interference between $\mathrm{COCl}_{2}$ and $\mathrm{CFC}-11$ by exploiting the MTR capability of our code to simultaneously retrieve both gases. We used MWMAKE to identify optimized MWs for the joint $\mathrm{COCl}_{2}$ and $\mathrm{CFC}-11$ retrieval. The selected MWs are listed in Table 1.

The main components of the resulting $\mathrm{COCl}_{2}$ error budget estimated by MWMAKE (Dudhia, 2007) are shown in Fig. 2. The total random component of the systematic error was calculated as the quadratic summation of all the errors that vary randomly from profile to profile. In our case this error includes uncertainties in temperature, pressure and interfering species that are not retrieved. The total systematic error was calculated as the quadratic summation of the errors that provide almost constant contribution to the total budget; therefore they produce a bias in the results. These errors are 
the uncertainties in the spectroscopic database, in the radiometric calibration of the measured spectra and in the parameterisation of the width of the instrumental line shape. The contribution of the new phosgene linelist to the spectroscopic error was calculated considering the uncertainties in the line intensities (3-5\%, we have conservatively assumed an error of $5 \%)$ and in the air-broadening coefficients $(20 \%)$. We have considered that an error of $5 \%$ in the line intensity leads to an error of the same percentage in the retrieved VMRs since the phosgene absorption is in the linear region. An uncertainty of $20 \%$ in the air-broadening coefficients produces an error of about $1 \%$ in the phosgene cross sections computed at an average stratospheric temperature and pressure. We have assumed that on average the retrieved VMRs will be affected by a similar error. In Fig. 2 we report (orange) the final spectroscopic error resulting from the quadratic summation of the uncertainties due to the spectroscopic data of the other molecules (estimated by MWMAKE) and the phosgene spectroscopic errors reported above. In Fig. 2 we also report (blue) the total error obtained as the quadratic summation of the total systematic and random error components.

The joint $\mathrm{COCl}_{2}$ and $\mathrm{CFC}-11$ retrieval assumes the profiles obtained from the sequential retrieval of the following targets: $p, T$ and VMR of $\mathrm{H}_{2} \mathrm{O}, \mathrm{O}_{3}, \mathrm{HNO}_{3}, \mathrm{NO}_{2}, \mathrm{CFC}$ 11, CFC-12, CFC-22. With this retrieval set-up, artefacts and non-physical features disappeared from the retrieved $\mathrm{COCl}_{2}$ profiles. Moreover the retrieval error now properly takes into account the correlation between $\mathrm{COCl}_{2}$ and CFC-11 VMR profiles, which is quantified by the off-diagonal elements of the covariance matrix of the retrieval (Dinelli et al., 2004). For the CFC-11 MTR analysis we used the same vertical retrieval grid adopted in the single target retrieval with the IG2 profile used as initial guess and a priori profiles with a covariance matrix set to $80 \%$ of the profile value. The correlation length for CFC-11 was the same used for phosgene. Differences between the CFC- 11 retrieved individually (assuming phosgene in climatological abundance) and CFC-11 retrieved jointly with phosgene were small, well within the noise error.

\section{Results}

An objective of this work is to demonstrate the feasibility of the phosgene retrieval from MIPAS spectra. Therefore, due to the computing resources required by a full mission retrieval, we considered adequate the use of a reduced data set. For this reason we selected 1 year (2008) and, to highlight possible seasonal and latitudinal variations of $\mathrm{COCl}_{2}$, we processed all MIPAS measurements acquired on days 18 and 20 of each month when MIPAS was measuring in the nominal observation mode (in 2008 this mode was used for only $80 \%$ of the time). In total we retrieved more than 28000 profiles.
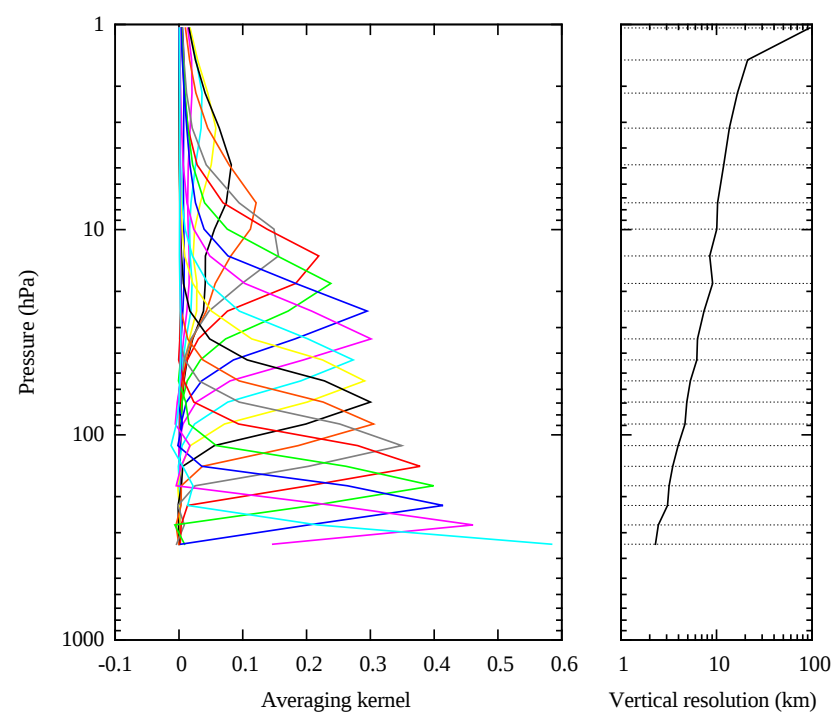

Figure 3. Typical phosgene averaging kernels (left) and vertical resolution (right). In the left panel each colour represents a row of the averaging kernel matrix. In the right panel we have also reported the pressure levels used for the retrieval. The plots refer to the retrieval from a MIPAS limb scan acquired on 18 March $2008,31^{\circ} \mathrm{N} / 75^{\circ} \mathrm{W}$

In the left panel of Fig. 3, we report the typical phosgene averaging kernels (AK) relative to a profile retrieved from a limb scan acquired on 18 March 2008 and geolocated at $31^{\circ} \mathrm{N} / 75^{\circ} \mathrm{W}$. The plot shows the sensitivity of the retrieved profile to various pressure levels in the UTLS region. From the analysis of all the averaging kernels of the retrievals we can deduce that our analysis has a high sensitivity between 10 and $400 \mathrm{hPa}$. Above $10 \mathrm{hPa}$ the AKs are less peaked, indicating lower sensitivity. In the right panel of Fig. 3 we plot, for the same AKs, the vertical resolution computed as the full width at half maximum (FWHM) of the rows of the AK. We note that in the altitude region with high sensitivity (10 $400 \mathrm{hPa}$ ) the vertical resolution ranges from 3 to $10 \mathrm{~km}$ while above $10 \mathrm{hPa}$ it becomes larger.

The final data set was filtered by selecting only the profile data points for which a significant amount of information was extracted from the measurements. This was done using an information gain threshold of 0.3. This means that the a priori error is reduced in the analysis by a factor of about 1.2. After filtering, the final set of data was divided into four groups according to their measurement dates: June, July and August (JJA); September, October and November (SON); December, January and February (DJF); March, April and May (MAM). Each of these groups represents a season. For each season, we calculated the average phosgene profile in the following latitude bands: North Pole $\left(90-65^{\circ} \mathrm{N}\right)$, midlatitude north $\left(65-20^{\circ} \mathrm{N}\right)$, equatorial north $\left(20-0^{\circ}\right)$, equatorial south $\left(0-20^{\circ} \mathrm{S}\right)$, midlatitude south $\left(20-65^{\circ} \mathrm{S}\right)$ and South Pole $\left(65-90^{\circ} \mathrm{S}\right)$. Since the MIPAS vertical sampling grid (also the retrieval grid) is not constant along the orbit, we first linearly 


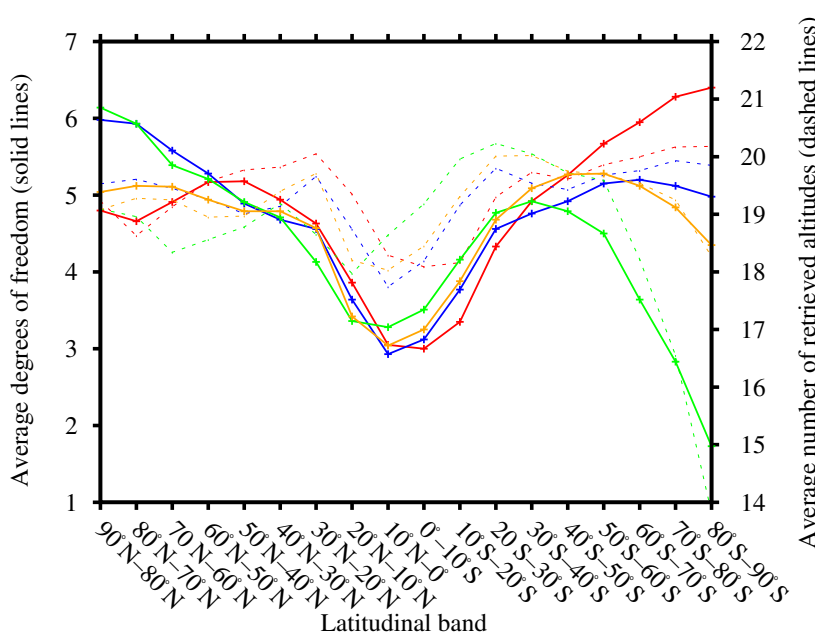

Figure 4. Average phosgene degrees of freedom (DOF, solid lines) and average of retrieved altitudes (dashed lines) for DJF (red), MAM (blue), JJA (green) and SON (orange). Averages are calculated for $10^{\circ}$ latitude bins.

interpolated in log pressure each individual retrieved profile on a fixed pressure grid and then we computed the averages.

In Fig. 4 we report, for $10^{\circ}$ latitude bins and each season, the average number of degrees of freedom (DOFs) (solid lines) and the corresponding average number of altitudes at which the phosgene profile is retrieved (dashed lines). The two curves show a reduction of the number of DOFs and of the number of retrieval altitudes in the tropical region for all seasons. This is caused by the presence of high-altitude clouds typical of this region. Clouds are in fact detected by the Level 2 preprocessor with a cloud-filtering algorithm (Raspollini et al., 2006, 2013) and the spectra flagged as "cloudy" are excluded from the analysis. The only noticeable seasonal dependence of the number of DOFs is in the polar regions. In the figure we also see that in JJA at the South Pole there is a significant reduction in both the number of retrieved profile altitudes and DOFs. This is due to the presence of polar stratospheric clouds (PSCs) detected and filtered out by the cloud detection algorithm.

Figure 5 shows the average VMR profiles of phosgene for the latitudinal bands and seasons described above. The plots in this figure do not show evident seasonal variability in the vertical distribution of phosgene in the middle and tropical latitude bands, in agreement with the discussion of Kindler et al. (1995). We only observe a weak seasonality in the polar regions. The reduction of phosgene observed at both poles during winter and spring is probably related to both the subsidence of stratospheric air due to the presence of the polar vortex and the reduction of phosgene formation rate due to photolysis. The average profiles show a clear latitude dependence. Actually, in the polar and midlatitude regions the average profiles do not exceed $30 \mathrm{pptv}$ and they do not show evident peaks. In contrast, in the tropical latitude bands, the
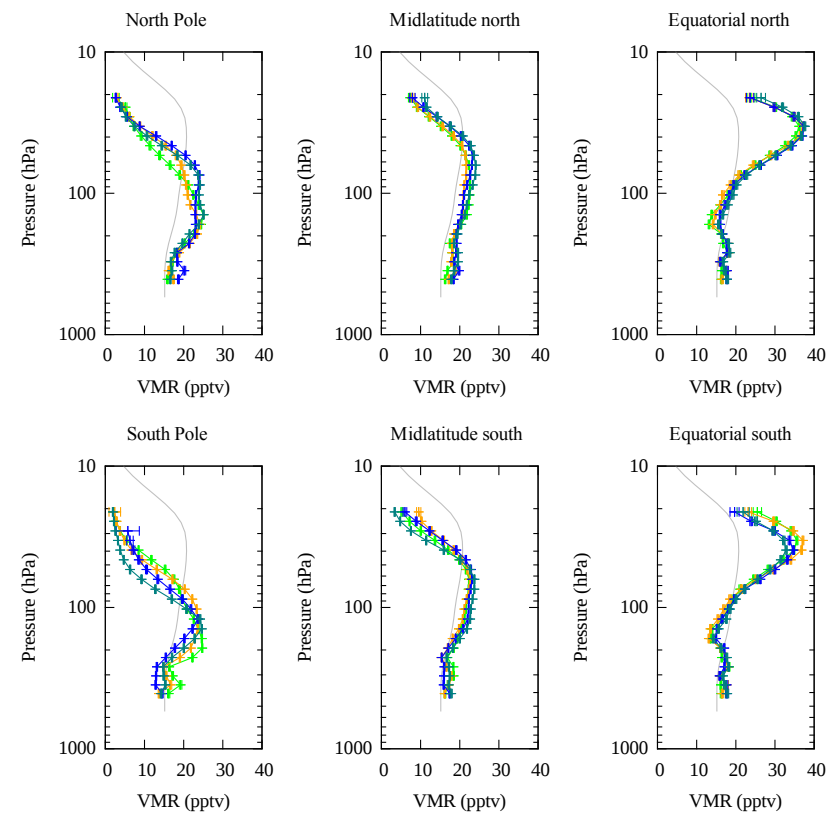

Figure 5. Average phosgene VMR profiles for DJF (green), MAM (orange), JJA (blue) and SON (light blue). Averages are calculated for North Pole $\left(90-65^{\circ} \mathrm{N}\right.$, top left), midlatitude north $\left(65-20^{\circ} \mathrm{N}\right.$, top centre), equatorial north (20- $0^{\circ}$, top right), South Pole (65$90^{\circ} \mathrm{S}$, bottom left), midlatitude south $\left(20-65^{\circ} \mathrm{S}\right.$, bottom centre) and equatorial south $\left(0-20^{\circ} \mathrm{S}\right.$, bottom right). We also report the a priori profile (solid grey) based on the existing climatology. This profile does not reproduce the observed geographical variability.

vertical VMR distributions show peak values close to $40 \mathrm{pptv}$ located at lower pressure levels with respect to the other regions. Figure 6 shows the zonal averages (for $10^{\circ}$ latitude bins) of phosgene VMR, for each season of the year 2008 . These maps highlight the latitudinal dependence of the phosgene distribution in the UTLS region. The symmetric pattern in which VMR values decrease moving from the equator to the poles is caused by the Brewer-Dobson circulation, which transports the tropical phosgene poleward. The equatorial bulk in the distribution of the $\mathrm{COCl}_{2}$ is caused by the greater insolation in the tropics compared to the higher latitudes (Fu et al., 2007).

\subsection{Comparison with ACE-FTS measurements}

To validate our results we used the phosgene data contained in version 3.5 of the measurements of the ACE-FTS instrument. ACE-FTS uses the solar occultation technique to make measurements in the spectral interval between 750 and $4400 \mathrm{~cm}^{-1}$, with a spectral resolution of $0.02 \mathrm{~cm}^{-1}$. Out of the whole ACE-FTS data set we selected the phosgene VMR profile co-located with the MIPAS measurements used in our analysis. The co-location criteria were $5^{\circ}$ maximum difference in latitude and longitude and a maximum difference of $6 \mathrm{~h}$ in the acquisition time. In total we found about $150 \mathrm{co}-$ 

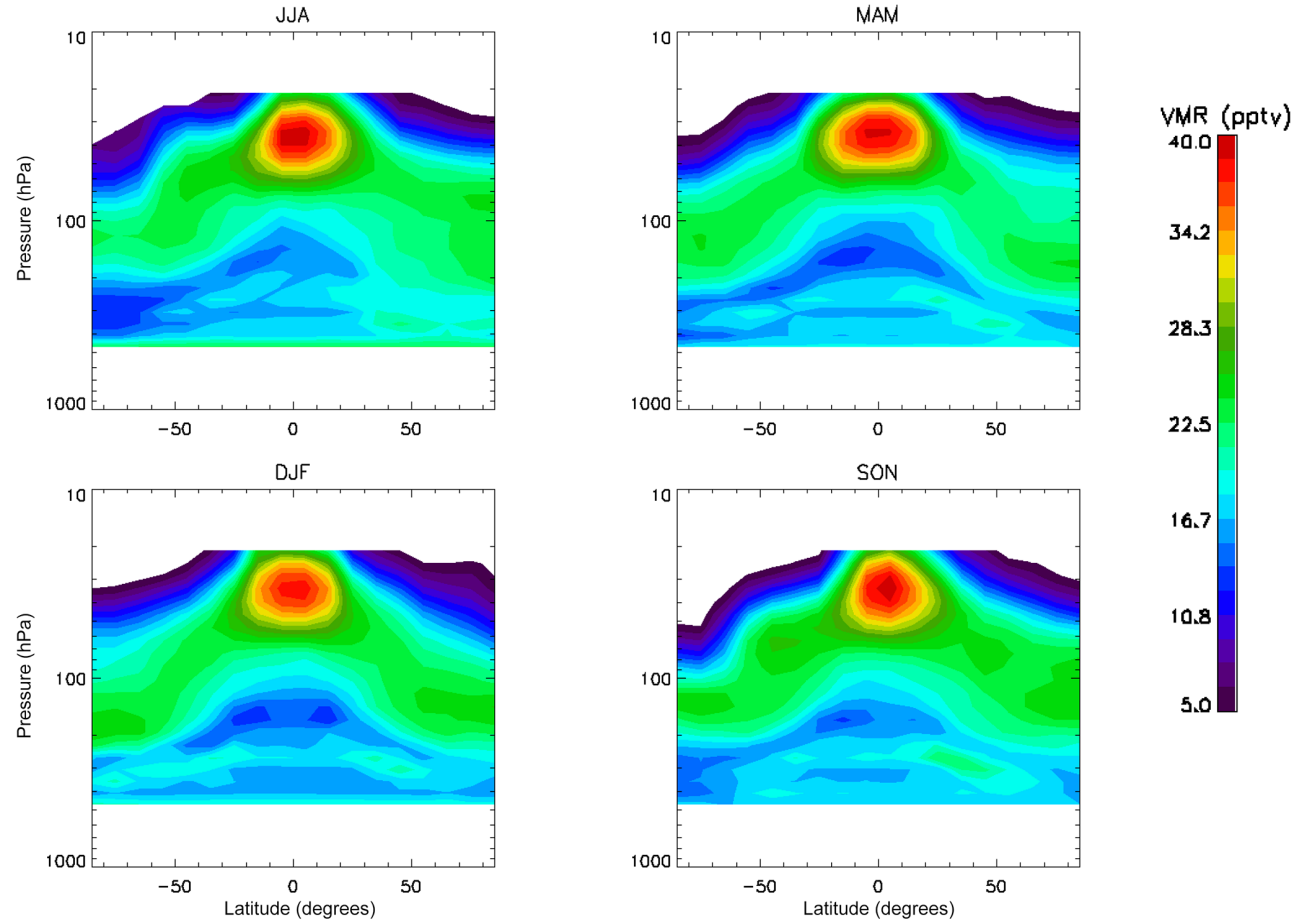

Figure 6. Zonal average phosgene VMR for JJA (top left), MAM (top right), DJF (bottom left) and SON (bottom right). Averages are calculated for $10^{\circ}$ latitude bins.

incidences. The ACE-FTS profiles were linearly interpolated in log pressure onto the same pressure grid used to calculate our averages. To remove unrealistic values we have filtered out the points of the ACE-FTS profiles for which the values exceeded the average value by more than 3 times the standard deviation. MIPAS data were filtered with the same criterion described in Sect. 4. We computed the differences between MIPAS and ACE-FTS co-located profiles and in Fig. 7 we report their average (red line). On the same figure we report (blue line) the combined systematic error of the difference, obtained as the square root of the sum of the squared systematic errors of each instrument. The percentage systematic error of the individual instruments was assumed constant for all the pressure levels and equal to $13 \%$ of the phosgene VMR value for MIPAS (an average value of the estimated systematic errors reported in Fig. 2) and, as reported in Fu et al. (2007), $30 \%$ of the VMR value for ACE-FTS. The average difference shown in Fig. 7 is consistent with zero, considering its combined systematic error (blue line) and the standard deviation of the mean (represented by the red line error bar in the figure) (von Clarmann, 2006). This suggests that MIPAS and ACE-FTS phosgene retrievals are in good agreement. The random error of the difference (green line in Fig. 7) is calculated as the square root of the sum of the squared random errors of MIPAS and ACE-FTS. This error should mimic the standard deviation of the differences represented by the yellow line in the figure. We see that the two error estimates are in good agreement below $50 \mathrm{hPa}$. Given the relatively small number of MIPAS and ACE-FTS co-located measurements it was not possible to perform the comparison of the two instruments on separate latitude bands and seasons.

\section{Conclusions}

The global distribution in the UTLS of $\mathrm{COCl}_{2}$ has been determined for the first time from MIPAS measurements. Due to the weak spectral signatures of phosgene and their interference with CFC-11 emission, it was possible to retrieve phosgene distribution only using the new functionality MTR of the ORM. This permits the joint retrieval of $\mathrm{COCl}_{2}$ and CFC-11 VMRs. We determined seasonal and latitudinal averages of phosgene VMR using more than 28000 profiles retrieved by our processor from a set of MIPAS measurements acquired in the year 2008. MIPAS limb measurements provide a global coverage of the UTLS region that enables the study of the seasonal variability of phosgene. Average seasonal profiles of phosgene show an evident latitudinal variability. Largest values of the $\mathrm{COCl}_{2} \mathrm{VMR}$ are found in the tropical regions where we observe values larger than $35 \mathrm{pptv}$ at pressures around $300 \mathrm{hPa}$. By contrast, in the midlatitude and polar regions, the VMR maximum values do not exceed $30 \mathrm{pptv}$ and the vertical distributions are less peaked. The consistency of our results was tested using ACE-FTS profiles of the phosgene co-located with the profiles we retrieved 


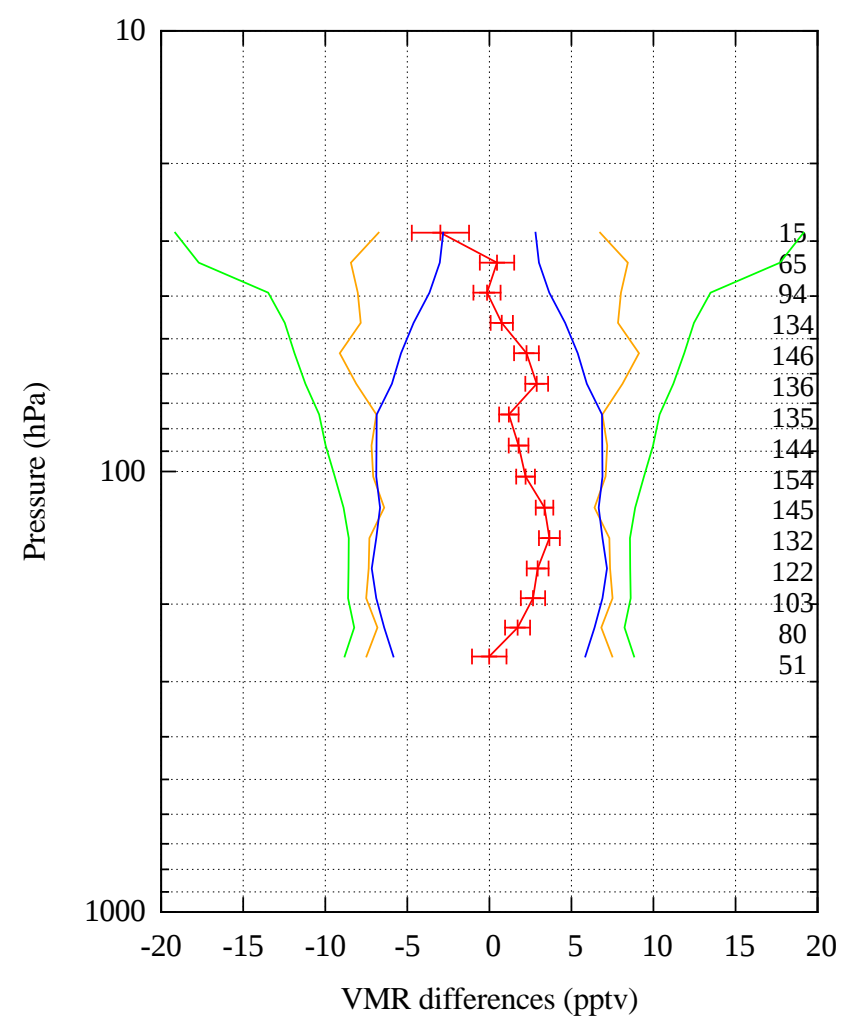

Figure 7. Average difference profile between the co-located MIPAS and ACE-FTS measurements (red) with standard deviation of the mean (red error bars). The standard deviation of the difference (orange-red), the total random error (green), the total systematic error of the difference (blue) are also reported. The number of colocated pairs for each pressure level is reported on the right side of the plot.

from MIPAS observations. We have observed a good agreement between the two instruments. It is worth noting that the high spatial and temporal sampling rates of MIPAS measurements highlight the latitudinal distribution of phosgene and, for the first time, its seasonal variations. In particular we found that in the UTLS the phosgene distribution has no seasonal variability in the tropics and at the midlatitudes, but weak seasonality is observed in the polar regions. The long time series of MIPAS measurements could in principle allow the study of trends for the phosgene distribution in the UTLS. However MIPAS Level 2 data are affected by systematic errors induced by the non-linear behaviour of the detectors (Kleinert et al., 2007), and the current radiometric calibration does not reach an adequate level of accuracy to perform an exhaustive trends analysis (Eckert et al., 2014; Kiefer et al., 2013). For this reason, and given the huge amount of computational resources required, we did not perform the phosgene retrieval from the full MIPAS mission, as it would be necessary to study possible trends in the VMR of this gas.

\section{Data availability}

MIPAS data used in this work is available upon request to the authors.

Acknowledgements. This study was supported by the ESA project "Support to MIPAS Level 2 processor Verification and Validation - Phase F" (ESRIN/Contract No. 4000112093/14/I-LG). The Atmospheric Chemistry Experiment (ACE), also known as SCISAT, is a Canadian-led mission mainly supported by the Canadian Space Agency and the Natural Sciences and Engineering Research Council of Canada.

Edited by: A. Richter

Reviewed by: two anonymous referees

\section{References}

Brown, A. T., Chipperfield, M. P., Boone, C., Wilson, C., Walker, K. A., and Bernath, P. F.: Trends in atmospheric halogen containing gases since 2004, J. Quant. Spectrosc. Ra., 112, 2552-2566, doi:10.1016/j.jqsrt.2011.07.005, 2011.

Brown, L. R., Gunson, M. R., Toth, R. A., Irion, F. W., Rinsland, C. P., and Goldman, A.: The 1995 Atmospheric Trace Molecule Spectroscopy (ATMOS) Linelist, Appl. Opt., 35, 2828-2848, doi:10.1364/AO.35.002828, 1996.

Dinelli, B., Alpaslan, D., Carlotti, M., Magnani, L., and Ridolfi, M.: Multi-target retrieval (MTR): the simultaneous retrieval of pressure, temperature and volume mixing ratio profiles from limbscanning atmospheric measurements, J. Quant. Spectrosc. Ra., 84, 141-157, doi:10.1016/S0022-4073(03)00137-7, 2004.

Dinelli, B. M., Castelli, E., Carli, B., Del Bianco, S., Gai, M., Santurri, L., Moyna, B. P., Oldfield, M., Siddans, R., Gerber, D., Reburn, W. J., Kerridge, B. J., and Keim, C.: Technical Note: Measurement of the tropical UTLS composition in presence of clouds using millimetre-wave heterodyne spectroscopy, Atmos. Chem. Phys., 9, 1191-1207, doi:10.5194/acp-9-1191-2009, 2009.

Dudhia, A.: MIPAS Microwindow error analysis, available at: www.atm.ox.ac.uk/group/mipas/err/, 2007.

Dudhia, A., Jay, V. L., and Rodgers, C. D.: Microwindow selection for high-spectral-resolution sounders, Appl. Opt., 41, 36653673, doi:10.1364/AO.41.003665, 2002.

Eckert, E., von Clarmann, T., Kiefer, M., Stiller, G. P., Lossow, S., Glatthor, N., Degenstein, D. A., Froidevaux, L., GodinBeekmann, S., Leblanc, T., McDermid, S., Pastel, M., Steinbrecht, W., Swart, D. P. J., Walker, K. A., and Bernath, P. F.: Drift-corrected trends and periodic variations in MIPAS IMK/IAA ozone measurements, Atmos. Chem. Phys., 14, 25712589, doi:10.5194/acp-14-2571-2014, 2014.

Engel, A., Bönisch, H., Schwarzenberger, T., Haase, H.-P., Grunow, K., Abalichin, J., and Sala, S.: Long-term validation of ESA operational retrieval (version 6.0) of MIPAS Envisat vertical profiles of methane, nitrous oxide, $\mathrm{CFC} 11$, and $\mathrm{CFC} 12$ using balloon-borne observations and trajectory matching, Atmos. Meas. Tech., 9, 1051-1062, doi:10.5194/amt-9-1051-2016, 2016. 
Fischer, H., Birk, M., Blom, C., Carli, B., Carlotti, M., von Clarmann, T., Delbouille, L., Dudhia, A., Ehhalt, D., Endemann, M., Flaud, J. M., Gessner, R., Kleinert, A., Koopman, R., Langen, J., López-Puertas, M., Mosner, P., Nett, H., Oelhaf, H., Perron, G., Remedios, J., Ridolfi, M., Stiller, G., and Zander, R.: MIPAS: an instrument for atmospheric and climate research, Atmos. Chem. Phys., 8, 2151-2188, doi:10.5194/acp-8-2151-2008, 2008.

Fu, D., Boone, C. D., Bernath, P. F., Walker, K. A., Nassar, R., Manney, G. L., and McLeod, S. D.: Global phosgene observations from the Atmospheric Chemistry Experiment (ACE) mission, Geophys. Res. Lett., 34, L17815, doi:10.1029/2007GL029942,, 2007.

Kellmann, S., von Clarmann, T., Stiller, G. P., Eckert, E., Glatthor, N., Höpfner, M., Kiefer, M., Orphal, J., Funke, B., Grabowski, U., Linden, A., Dutton, G. S., and Elkins, J. W.: Global CFC-11 $(\mathrm{CCl} 3 \mathrm{~F})$ and $\mathrm{CFC}-12(\mathrm{CCl} 2 \mathrm{~F} 2)$ measurements with the Michelson Interferometer for Passive Atmospheric Sounding (MIPAS): retrieval, climatologies and trends, Atmos. Chem. Phys., 12, 11857-11875, doi:10.5194/acp-12-11857-2012, 2012.

Kiefer, M., Aubertin, G., Birk, M., de Laurentis, M., Eckert, E., Kleinert, A., Perron, G., and Wagner, G.: Impact of Improved Corrections for MIPAS Detector Non-Linearity, Atmospheric Composition Validation and Evolution, 38, ESA, Abstract Book, Frascati, 2013.

Kindler, T. P., Chameides, W. L., Wine, P. H., Cunnold, D. M., Alyea, F. N., and Franklin, J. A.: The fate of atmospheric phosgene and the stratospheric chlorine loadings of its parent compounds: $\mathrm{CCl} 4, \mathrm{C} 2 \mathrm{Cl} 4, \mathrm{C} 2 \mathrm{HCl} 3, \mathrm{CH} 3 \mathrm{CCl} 3$, and $\mathrm{CHCl} 3$, J. Geophys. Res.-Atmos., 100, 1235-1251, doi:10.1029/94JD02518, 1995.

Kleinert, A., Aubertin, G., Perron, G., Birk, M., Wagner, G., Hase, F., Nett, H., and Poulin, R.: MIPAS Level 1B algorithms overview: operational processing and characterization, Atmos. Chem. Phys., 7, 1395-1406, doi:10.5194/acp-7-13952007, 2007.

Kwabia-Tchana, F., Lafferty, W., Flaud, J.-M., Manceron, L., and Ndao, M.: High-resolution analysis of the $v_{1}$ and $v_{5}$ bands of phosgene ${ }^{35} \mathrm{Cl}_{2} \mathrm{CO}$ and ${ }^{35} \mathrm{Cl}^{37} \mathrm{ClCO}$, Mol. Phys., 113, 32413246, doi:10.1080/00268976.2015.1015638, 2015.

ML2PP: Readme file of MIPAS ESA Level 2 products Version 6 ENVI-GSOP-EOGD-QD-12-0116, 2012.

Perrin, A., Flaud, J.-M., Ridolfi, M., Vander Auwera, J., and Carlotti, M.: MIPAS database: new $\mathrm{HNO}_{3}$ line parameters at $7.6 \mu \mathrm{m}$ validated with MIPAS satellite measurements, Atmos. Meas. Tech., 9, 2067-2076, doi:10.5194/amt-9-2067-2016, 2016.

Raspollini, P., Belotti, C., Burgess, A., Carli, B., Carlotti, M., Ceccherini, S., Dinelli, B. M., Dudhia, A., Flaud, J.-M., Funke, B., Höpfner, M., López-Puertas, M., Payne, V., Piccolo, C., Remedios, J. J., Ridolfi, M., and Spang, R.: MIPAS level 2 operational analysis, Atmos. Chem. Phys., 6, 5605-5630, doi:10.5194/acp6-5605-2006, 2006.

Raspollini, P., Carli, B., Carlotti, M., Ceccherini, S., Dehn, A., Dinelli, B. M., Dudhia, A., Flaud, J.-M., López-Puertas, M., Niro, F., Remedios, J. J., Ridolfi, M., Sembhi, H., Sgheri, L., and von Clarmann, T.: Ten years of MIPAS measurements with ESA Level 2 processor V6 - Part 1: Retrieval algorithm and diagnostics of the products, Atmos. Meas. Tech., 6, 2419-2439, doi:10.5194/amt-6-2419-2013, 2013.
Remedios, J. J., Leigh, R. J., Waterfall, A. M., Moore, D. P., Sembhi, H., Parkes, I., Greenhough, J., Chipperfield, M. P., and Hauglustaine, D.: MIPAS reference atmospheres and comparisons to V4.61/V4.62 MIPAS level 2 geophysical data sets, Atmos. Chem. Phys. Discuss., 7, 9973-10017, doi:10.5194/acpd-79973-2007, 2007.

Ridolfi, M., Carli, B., Carlotti, M., von Clarmann, T., Dinelli, B. M., Dudhia, A., Flaud, J.-M., Höpfner, M., Morris, P. E., Raspollini, P., Stiller, G., and Wells, R. J.: Optimized Forward Model and Retrieval Scheme for MIPAS Near-Real-Time Data Processing, Appl. Opt., 39, 1323-1340, doi:10.1364/AO.39.001323, 2000.

Rodgers, C. D.: Inverse methods for atmospheric sounding: Theory and Practice, Series on Atmospheric, Oceanic and Planetary Physics, Vol. 2, World Scientific Publishing Co., Singapore, 2000.

Schmidt, U., Kulessa, G., Klein, E., Roeth, E.-P., and Fabian, P.: Intercomparison of ballloon-borne cryogenic whole air samplers during the MAP/GLOBUS 1983 campaign, Planet. Space Sci., 35, 647-656, doi:10.1016/0032-0633(87)90131-0, 1987.

Sharpe, S. W., Johnson, T. J., Sams, R. L., Chu, P. M., Rhoderick, G. C., and Johnson, P. A.: Gas-Phase Databases for Quantitative Infrared Spectroscopy, Appl. Spectrosc., 58, 1452-1461, doi:10.1366/0003702042641281, 2004.

Singh, H. B.: Phosgene in the ambient air, Nature, 264, 428-429, doi:10.1038/264428a0, 1976.

Steck, T. and von Clarmann, T.: Constrained Profile Retrieval Applied to the Observation Mode of the Michelson Interferometer for Passive Atmospheric Sounding, Appl. Opt., 40, 3559-3571, doi:10.1364/AO.40.003559, 2001.

Toon, G. C., Blavier, J.-F., Sen, B., and Drouin, B. J.: Atmospheric $\mathrm{COCl}_{2}$ measured by solar occultation spectrometry, Geophys. Res. Lett., 28, 2835-2838, doi:10.1029/2000GL012156, 2001.

von Clarmann, T.: Validation of remotely sensed profiles of atmospheric state variables: strategies and terminology, Atmos. Chem Phys., 6, 4311-4320, doi:10.5194/acp-6-4311-2006, 2006.

Wetzel, G., Oelhaf, H., Friedl-Vallon, F., Kleinert, A., Maucher, G., Nordmeyer, H., and Orphal, J.: Long-term intercomparison of MIPAS additional species $\mathrm{ClONO}_{2}, \mathrm{~N}_{2} \mathrm{O}_{5}, \mathrm{CFC}-11$, and CFC-12 with MIPAS-B measurements, Ann. Geophys., 56 , doi:10.4401/ag-6329, 2014.

Wilson, S. R., Crutzen, P. J., Schuster, G., Griffith, D. W. T., and Helas, G.: Phosgene measurements in the upper troposphere and lower stratosphere, Nature, 334, 689-691, doi:10.1038/334689a0, 1988. 